\title{
PEMISAHAN GAS CO, BIOGAS MENGGUNAKAN ALAT WATER SCRUBBER DENGAN VARIASI LAJU ALIR DAN TEKANAN BIOGAS
}

\author{
Tina Mulya Gantina, Kartono, Maridjo dan Arief ardiansyah \\ Jurusan Teknik Konversi Energi, Politeknik Negeri Bandung \\ Jl. Geger Kalong Hilir, Ciwaruga, Bandung \\ e-mail: tinapolban@yahoo.co.id
}

\begin{abstract}
Biogas is produced from fermentation of organic materials such as domestic waste and manure from animal husbandary. To increase the quality of biogas as a fuel, it has to be followed by the the increasing of $\mathrm{CH}_{4}$ concentration. It could be done with seperating $\mathrm{CH}_{4}$ from other gases such as $\mathrm{CO}_{2}$. One of separation methode is using a water scrubber with water act as medium which as $\mathrm{CO}_{2}$ is more soluable to water than $\mathrm{CH}_{4}$. The result showed that $\mathrm{CO}_{2}$ absorption was increased followed by the increasing of the pressure and the biogas flow rate. The percentage of $\mathrm{CO}_{2}$ absorption at $2,5 \mathrm{~m}^{3} /$ hour of biogas flow rate and 8 bar was 4,6 $\%$, meanwhile it was $11,1 \%$ at 10 bar. In the other side, there was $9,5 \%$ of $\mathrm{CH}_{4}$ increasing at 10 bar. Therefore, $\mathrm{CO}_{2}$ separation from biogas using water scrubber at 10 bar is better than at 8 bar.
\end{abstract}

Keywords : water scrubber, $\mathrm{CO}_{2}$ separation, biogas, water absorber.

\section{PENDAHULUAN}

Pada beberapa tahun terakhir ini, permasalahan energi terutama di Indonesia merupakan permasalahan yang cukup krusial. Peningkatan permintaan energi yang disebabkan oleh makin meningkatnya jumlah penduduk, melambungnya harga bahan bakar minyak dan makin menipisnya sumber minyak bumi, telah memaksa masyarakat untuk mencari energi alternatif lain sebagai pengganti bahan bakar minyak.

Biogas merupakan salah satu bahan bakar alternatif yang bersifat ramah lingkungan dengan komponen utama gas metana $\left(\mathrm{CH}_{4}\right)$ yang dihasilkan dari proses degradasi bahan organik seperti kotoran hewan, sisa makanan dan sampah organik, sehingga biogas dapat dijadikan sebagai bahan bakar alternatif pengganti bahan bakar minyak yang dapat mengatasi permasalahan energi saat ini. Di samping itu, teknologi pembuatan biogas termasuk teknologi yang cukup murah. Tetapi, biogas yang dihasilkan langsung dari proses degradasi kotoran hewan dalam kondisi yang optimal memiliki kandungan metan $\left(\mathrm{CH}_{4}\right)$ yang tidak terlalu tinggi atau hanya sekitar $60-70 \%$, sisanya adalah gas $\mathrm{CO}_{2}(30-40 \%)$ dan gas pengotor lainnya seperti $\mathrm{O}_{2}, \mathrm{~N}_{2}$ dan $\mathrm{H}_{2} \mathrm{~S}$ dalam jumlah kecil. Oleh karena itu, untuk lebih meningkatkan kualitas biogas sebagai bahan bakar, diperlukan suatu metoda untuk lebih meningkatkan kandungan gas metana dalam biogas.

Salah satu metoda yang digunakan untuk proses peningkatan kandungan gas metana dalam biogas adalah water scrubber dengan media air sebagai penyerap gas $\mathrm{CO}_{2}$, karena gas $\mathrm{CO}_{2}$ bersifat lebih larut dalam air dibandingkan gas metana. Prinsip kerja dari water scrubber yaitu dengan menggunakan aliran berlawanan (counter flow) dimana biogas dialirkan dari arah bawah ke atas sedangkan air di alirkan dari arah atas ke bawah. Diharapkan $\mathrm{CO}_{2}$ yang terserap air akan terbawa ke bawah bersama-sama aliran air sedangkan gas metana akan naik ke bagian atas. Berdasarkan hal-hal tersebut, pada penelitian ini akan dilakukan pengujian penyerapan gas $\mathrm{CO}_{2}$ biogas menggunakan alat water scrubber dengan variasi laju alir dan tekanan biogas sehingga dihasilkan kandungan gas metana yang lebih tinggi.

\section{METODOLOGI \\ Bahan dan alat yang digunakan}

1. Biogas sebanyak $3 \mathrm{~m} 3$ pada tekanan 1 bar.

2. Air pengumpan.

3. Satu set water scrubber, kapasitas $10 \mathrm{~m} 3$;

4. Termometer;

5. Pressure gauge;'

6. Flow meter. 


\section{Tahap-tahap Penelitian}

a. Sampel biogas

Biogas yang digunakan dalam pengujian ini diambil dari biodigester peternakan sapi di daerah Cilengkrang-Ujung Berung yang dikembangkan oleh LIPI.

b. Pengujian Komposisi Biogas

Komposisi biogas terutama kandungan $\mathrm{CO}_{2}$ dan $\mathrm{CH}_{4}$ nya sebelum dan setelah melewati water scrubber, diuji di laboratorium Instrumentasi Departemen Teknik Kimia ITB (Labtek X) dengan menggunakan alat gas chromatography.

c. Penampungan Biogas

Biogas yang akan dipakai untuk proses pemisahan $\mathrm{CO}_{2}$ dengan menggunakan alat water scrubber terlebih dahulu ditampung di dalam tabung penampung.

d. Pengujian Pemisahan $\mathrm{CO}_{2}$ Biogas

Pengujian pemisahan $\mathrm{CO}_{2}$ biogas atau pemurnian gas $\mathrm{CH}_{4}$ biogas dilakukan dengan cara mengumpankan air pada bagian atas menara water scrubber pada tekanan dan laju alir tertentu, sementara itu biogas dialirkan pada bagian bawah kolom (menara water scrubber). Gas dan cairan akan saling kontak dan terjadi reaksi kimia. Jumlah $\mathrm{CO}_{2}$ yang terserap akan dianalisa dengan menggunakan alat Gas Chromatograf. Laju aliran air sistem diukur dengan menggunakan flow meter yang telah dikalibrasi yang terletak pada keluaran pompa. Alat ukur laju aliran gas terletak pada keluaran kompresor dimana indikatornya terletak pada kotak panel. Untuk tekanan masuk diukur dengan menggunakaan pressure gauge pada keluaran kompresor. Sedangkan pressure gauge pada bagian atas scrubber digunakan untuk melihat tekanan pada scrubber.

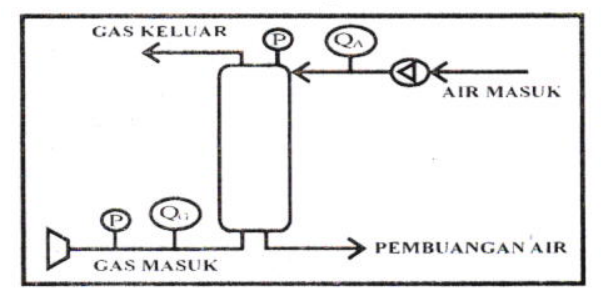

Gambar 1. Proses Pemisahan $\mathrm{CO}_{2}$ Biogas dengan water scrubber

\section{Parameter pengujian}

Laju aliran air sebesar $1,8 \mathrm{~m}^{3} / \mathrm{h}$.

Tekanan konstan: 10 bar dan 8 bar.

Temperatur lingkungan: $25^{\circ} \mathrm{C}$.

Laju aliran gas: $1 \mathrm{~m}^{3} / \mathrm{h} ; 1,5 \mathrm{~m}^{3} / \mathrm{h} ; 2 \mathrm{~m}^{3} / \mathrm{h} ; 2,5$ $\mathrm{m}^{3} / \mathrm{h}$.

\section{HASIL DAN PEMBAHASAN \\ Pengaruh laju alir biogas terhadap kandungan $\mathrm{CO}_{2}$ dan persen penyerapan $\mathrm{CO}_{2}$}

Berdasarkan data hasil pengujian diperoleh grafik hubungan kandungan $\mathrm{CO}_{2}$ sebelum dan sesudah melewati water scrubber pada tekanan biogas 8 bar dan 10 bar, seperti Gambar 2.a dan 2.b, serta grafik persen penyerapan gas $\mathrm{CO}_{2}$ pada tekanan biogas 8 dan 10 bar dengan alat water scrubber tersebut yang ditunjukkan pada Gambar 3.

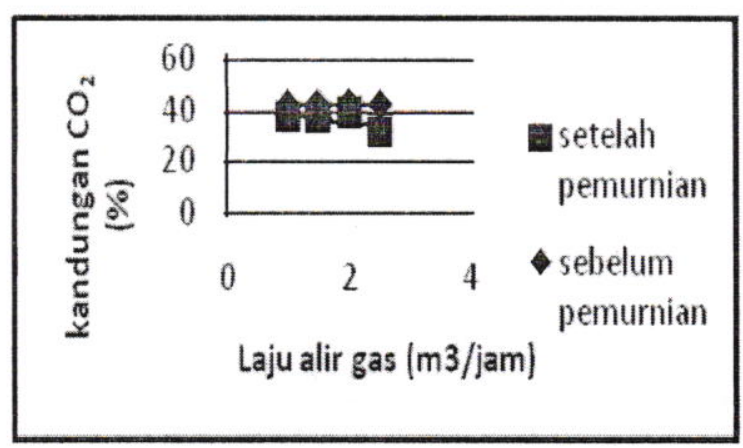

Tekanan 8 bar

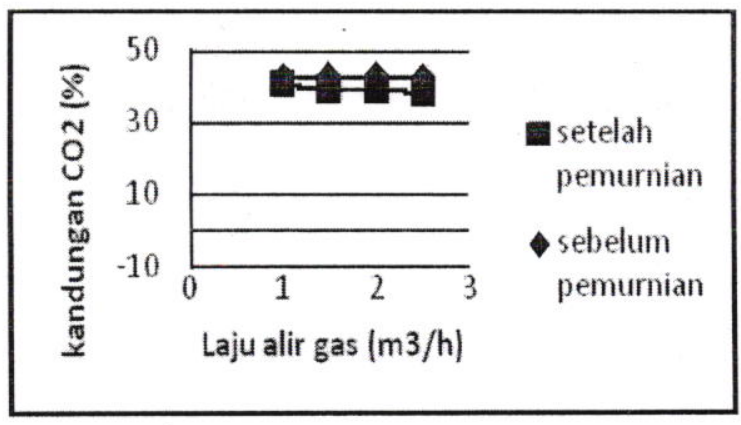

Tekanan 10 bar

Gambar 2. Hubungan laju aliran biogas terhadap kandungan $\mathrm{CO}_{2}$ pada tekanan 8 bar dan 10 bar 


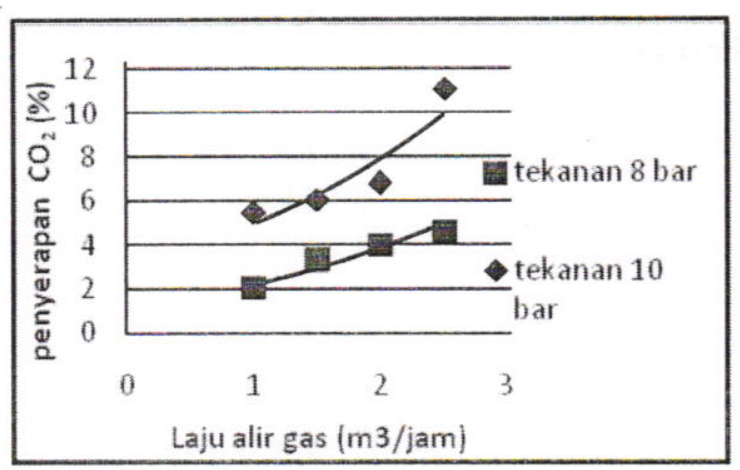

Gambar 3. Penyerapan $\mathrm{CO} 2$ terhadap laju aliran biogas pada tekanan 8 dan 10 bar

Pada Gambar 2.a dan 2.b terlihat bahwa makin besar laju alir biogas baik pada tekanan biogas 8 bar maupun 10 bar maka kandungan $\mathrm{CO}_{2}$ biogas setelah pemisahan makin berkurang. Pada kedua gambar tersebut juga terlihat bahwa pada biogas dengan kandungan gas $\mathrm{CO}_{2}$ awal yang sama yaitu $42,7 \%$, maka setelah melalui proses pemisahan pada tekanan 8 bar dengan laju alir biogas paling besar yaitu $2,5 \mathrm{~m} 3 / \mathrm{jam}$, kandungan gas $\mathrm{CO}_{2}$ menjadi $38,1 \%$ sedangkan pada tekanan 10 bar menjadi $31,7 \%$. Dari data tersebut terlihat bahwa selisih kandungan $\mathrm{CO}_{2}$ sebelum dan setelah pemisahan pada tekanan 8 bar lebih kecil dibandingkan pada 10 bar. Dengan demikian dapat dikatakan bahwa pemisahan $\mathrm{CO}_{2}$ biogas dengan alat water scrubber pada tekanan 10 bar lebih baik dan menghasilkan pemisahan $\mathrm{CO}_{2}$ yang lebih tinggi dibandingkan pada 8 bar.

Hal ini juga didukung dengan nilai persen penyerapan kandungan $\mathrm{CO}_{2}$ pada Gambar 3, dengan tekanan 10 bar menunjukkan persen penyerapan yang lebih besar dibandingkan pada 8 bar. Persen penyerapan $\mathrm{CO}_{2}$ pada laju aliran biogas yang paling besar yaitu $2,5 \mathrm{~m} 3 / \mathrm{jam}$ adalah sebesar $11,1 \%$ untuk tekanan biogas 10 bar dan hanya $4,6 \%$ untuk tekanan biogas 8 bar. Hal tersebut terjadi karena dengan semakin besarnya tekanan dan laju aliran biogas akan menghasilkan gaya gesek yang semakin besar sehingga lebih memudahkan air untuk menyerap/memisahkan $\mathrm{CO}_{2}$ dalam biogas.

Pengaruh laju alir biogas terhadap kandungan $\mathrm{CH}_{4}$ dan persen peningkatan $\mathrm{CH}_{4}$

Hubungan kandungan $\mathrm{CH}_{4}$ sebelum dan sesudah melewati alat water scrubber pada tekanan biogas 8 bar dan 10 bar ditunjukkan pada Gambar 4.a dan 4.b, serta grafik hubungan persen peningkatan gas $\mathrm{CH}_{4}$ pada tekanan biogas
8 dan 10 bar dengan alat water scrubber tersebut ditunjukkan pada Gambar 5.

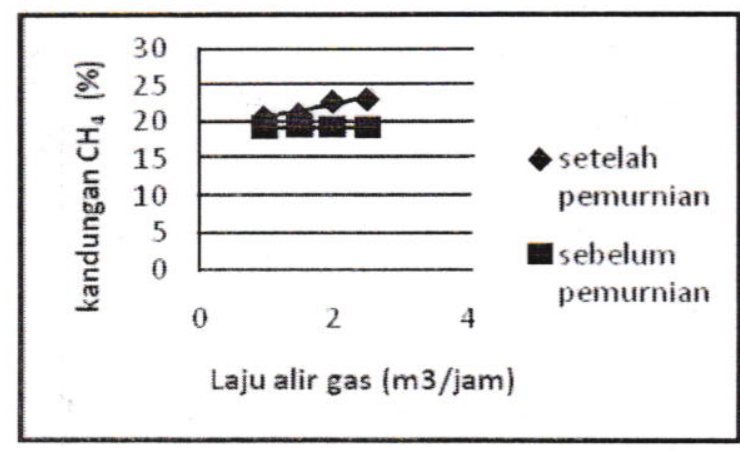

tekanan 8 bar

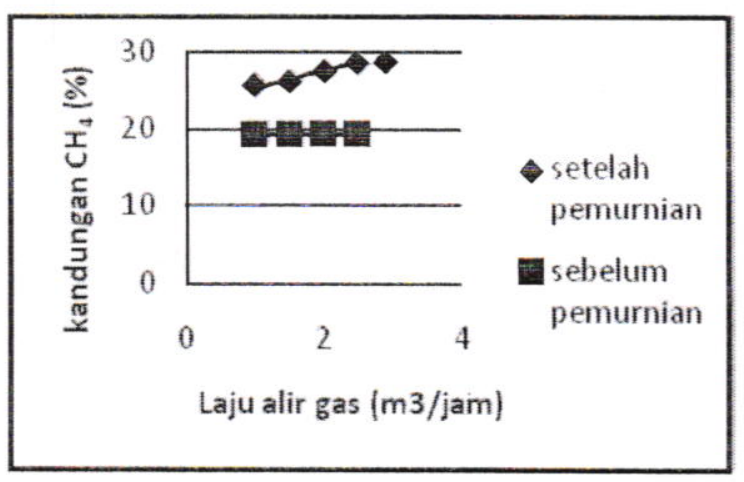

tekanan 10 bar

Gambar 4. Hubungan laju aliran biogas terhadap kandungan $\mathrm{CH}_{4}$ pada tekanan 8 bar dan 10 bar

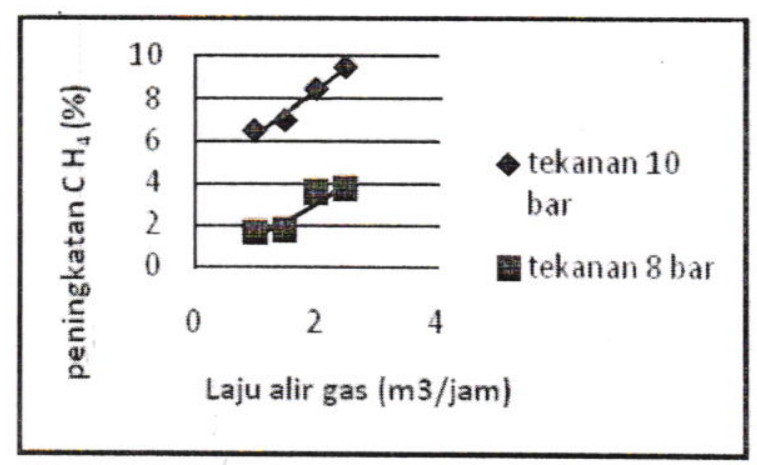

Gambar 5. Hubungan laju aliran biogas terhadap persen peningkatan $\mathrm{CH}_{4}$ pada tekanan 8 dan 10 bar

Pada Gambar 4.a dan 4.b terlihat bahwa makin besar laju alir biogas baik pada tekanan biogas 8 bar maupun 10 bar maka kandungan $\mathrm{CH}_{4}$ biogas setelah pemisahan makin meningkat. Pada kedua gambar tersebut juga terlihat bahwa pada biogas dengan kandungan gas $\mathrm{CH}_{4}$ awal yang sama yaitu $19,3 \%$, maka setelah melalui proses pemisahan pada tekanan 8 bar dengan laju alir biogas paling besar yaitu 2,5 m3/jam, kandungan 
gas $\mathrm{CH}_{4}$ menjadi $23,1 \%$, sedangkan pada tekanan 10 bar menjadi 28,6\%. Dari data tersebut terlihat bahwa selisih kandungan $\mathrm{CH}_{4}$ sebelum dan setelah pemisahan pada tekanan 8 bar lebih kecil dibandingkan pada 10 bar. Dengan demikian dapat dikatakan bahwa peningkatan $\mathrm{CH}_{4}$ biogas dengan alat water scrubber pada tekanan 10 bar lebih baik dan menghasilkan kandungan $\mathrm{CH}_{4}$ yang lebih tinggi dibandingkan pada 8 bar.

Persen peningkatan $\mathrm{CH}_{4}$ pada laju aliran biogas yang paling besar yaitu $2,5 \mathrm{~m} 3 / \mathrm{jam}$ adalah sebesar $9,5 \%$ untuk tekanan biogas 10 bar dan hanya 3,8\% untuk tekanan biogas 8 bar. Hal tersebut terjadi karena dengan semakin besarnya tekanan dan laju aliran biogas akan menghasilkan gaya gesek yang semakin besar sehingga lebih memudahkan air untuk menyerap/memisahkan $\mathrm{CO}_{2}$ sehingga kandungan $\mathrm{CH}_{4}$ dalam biogas akan meningkat.

Pada hasil penelitian ini juga terlihat bahwa media air berperan sebagai media pemisah/penyerap gas $\mathrm{CO}_{2}$ dalam biogas sehingga konsentrasi gas $\mathrm{CH}_{4}$ dalam biogas dapat menjadi lebih tinggi (lebih murni), karena gas $\mathrm{CO}_{2}$ lebih mudah larut dengan air dibandingkan dengan gas metan $\left(\mathrm{Ch}_{4}\right)$.

\section{KESIMPULAN}

Pada biogas dengan kandungan awal $\mathrm{CO}_{2}$ sebesar $42,7 \%$ dan kandungan $\mathrm{CH}_{4}$ sebesar $19,3 \%$, setelah dilakukan proses pemisahan dengan alat water scrubber pada laju alir biogas $2,5 \mathrm{~m}^{3} / \mathrm{jam}$, maka kandungan gas $\mathrm{CO}_{2}$ pada tekanan 8 bar berkurang menjadi 38,1 \% sedangkan pada tekanan 10 bar menjadi $31,7 \%$. Kandungan $\mathrm{CH}_{4}$ meningkat menjadi $23,1 \%$ pada tekanan 8 bar dan menjadi $28,6 \%$ pada tekanan 10 bar.

Persen penyerapan $\mathrm{CO}_{2}$ pada laju aliran biogas $2,5 \mathrm{~m} 3 /$ jam adalah sebesar $11,1 \%$ pada tekanan biogas 10 bar dan hanya $4,6 \%$ pada tekanan biogas 8 bar. Sedangkan kandungan $\mathrm{CH}_{4}$ terjadi peningkatan sebesar $3,8 \%$ pada tekanan biogas 8 bar dan sebesar $9,5 \%$ pada tekanan 10 bar Dengan kata lain, pada laju aliran air yang sama dengan makin besarnya tekanan dan laju aliran biogas maka penyerapan $\mathrm{CO}_{2}$ makin besar. Hal ini dikarenakan gaya gesek yang dihasilkan oleh air dan gas makin besar sehingga akan lebih memudahkan air untuk menyerap/memisahkan $\mathrm{CO}_{2}$ dalam biogas.

\section{DAFTAR PUSTAKA}

1. Bajracharya Tri Ratna. 2007, Purification And Compression of Biogas: a Research Experience, Journal of the Institute of Engineering, Vol. 7, No. 1, pp. 1-9.

2. Ofori-Boateng and E.M. Kwofie.2009, Water Scrubbing: A Better Option for Biogas Purification for Effective Storage, World Applied Sciences Journal 5, hal. 122125 .

3. Deublein. D and Steinhauser.A. 2008, Biogas from Waste and Renewable Resources, Germany.

4. Fuad Maarif dan Januar Arif .F.2004, Absorbsi Gas Karbondioksida $\left(\mathrm{CO}_{2}\right)$ dalam Biogas dengan Larutan $\mathrm{NaOH}$ secara Kontinyu, Jurusan Teknik Kimia, Fakultas Teknik, Universitas Diponegoro Semarang.

5. Kartohardjono. S, Sari. M, dan Yuliusman.2009,Absorbsi $\mathrm{CO}_{2}$ Melalui Kontaktor Membran Serat berongga Menggunakan Pelarut Air Dan Larutan 0.01 M NaOH, Depok.

6. Nozic. M.2006, Removal of carbon dioxide from biogas, Department of Chemical Engineering, Lund University, Sweden.

7. Petterson. A dan Wellinger. A. 2007, Biogas Upgrading Technologies, Development, And Innovations, IEA bioenergy, Sweden.

8. S. Kartohardjono, Eva F. Karamah, Z. Ahmad dan Distria R.2009, Asborpsi $\mathrm{CO}_{2}$ Melalui Kontaktor Membran Serat Berongga, Departemen Teknik Kimia, Fakultas Teknik Universitas Indonesia.

9. Wellinger. A. 2007, Biogas Upgrading, IEA bioenergy, Sweden.

10. Virendra K. Vijay1, Ram Chandra1, Parchuri M. V. Subbarao and Shyam S. Kapdi.2006, "Biogas Purification and Bottling into CNG Cylinders: Producing Bio-CNG from Biomass for Rural Automotive Applications", The 2nd Joint International Conference on "Sustainable Energy and Environment", Bangkok, Thailand 